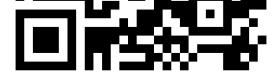

\title{
Narrativas Aquendadas:
} (Micro)Políticas de Negociação Estabelecidas por uma Estudante Trans* no Ensino Superior

Madson de Santana SANTOS, Universidade Federal de Sergipe. Alfrancio Ferreira DIAS, Universidade Federal de Sergipe.

Resumo: O propósito deste texto é refletir sobre o processo formativo de uma estudante trans*, a partir das (micro)políticas de negociações de gênero e sexualidade no ensino superior. Utilizou-se uma abordagem qualitativa pós-crítica, por meio da realização de entrevista narrativa, onde uma estudante trans* narra suas experiências de violências e lutas diárias. As narrativas confirmam as experiências transfóbicas vivenciadas pela estudante durante seu processo de escolarização, principalmente no ensino superior, assim como também evidencia possibilidades de (re)existência e (re)negociações das aprendizagens de gênero dentro da universidade, num processo de aquendar-se e desanquendar-se, sendo preciso (re)negociar-se enquanto pessoa trans*.

Palavras-Chave: Negociação de Gênero. Estudantes Trans*. Ensino Superior. 


\section{Introdução}

“Não, não é fácil escrever. É duro como quebrar rochas. Mas voam faíscas e lascas como aços espelhados.

Ah que medo de começar, e ainda nem sequer sei o nome da moça. Sem falar que a história me desespera por ser complexa- demais. O que me proponho contar parece fácil e à mão de todos. Mas sua elaboração é muito difícil. Pois tenho que tornar nítido o que está quase apagado e que mal vejo. Com mãos de dedos duros enlameados apalpar o invisível na própria lama.

De uma coisa tenho certeza: essa narrativa mexerá com uma coisa delicada: a criação de uma pessoa inteira, que na certa está tão viva quanto eu. Cuidai dela porque meu poder é só mostra-la para que vós a reconheçais na rua, andando de leve por causa da esvoaçada magreza. E se for triste minha narrativa? Depois na certa escreverei algo alegre, embora alegre por quê? Porque também sou homem de hosanas e um dia, quem sabe, cantarei loas que não as dificuldades da nordestina." (LISPECTOR, 1988, p.19).

Historicamente, a nós, sujeitos construídos e auto referenciados nas bordas de uma sociedade regrada pela heteronormatividade hegemônica, foi-se atribuído, com escassez e sob os poucos direitos que nos restaram, uma espécie de "consentimento" para a construção de nossas vidas e nossas subjetividades à partir das fronteiras - local que marca e estabelece diferenças, e que nunca se constitui como parte de uma totalidade, ou de um centro, sempre a partir da zona do não habitável -, espaços lidos como contextos de escória e onde se confere o label da marginalização social.

$\mathrm{O}$ processo de aquendar-se ${ }^{1}$ sempre esteve presente enquanto estratégia de fuga e sobrevivência das pessoas a quem nos propomos aqui discutir e analisar narrativas. Tomando como um empréstimo linguístico, advindo etimologicamente das línguas nagô e yorubá, e bem adequandose ao português Brasileiro, caracterizando-se então como parte essencial do dialeto pajubá, sem descaracterizar-se enquanto verbo transgressivo/transitivo. Procuramos nos utilizar do termo aquendar como um

${ }^{1}$ O termo aquendar/acuendar é muito utilizado principalmente por Travestis e Transexuais dentro do universo LGBTQIA+, como uma acepção do verbo esconder. De acordo com o dicionário informal, o aquendar "é o ato de se olhar no espelho com o pau entre as pernas" (RANNIERY, 2016, p.336). 
processo de inversão do verbo, ou seja, ao invés de escondermos ou aquendarmos, discursos, sujeitos e narrativas, iremos trabalhar na perspectiva da desaquendação, em específico da pessoa presente no texto. Neste percurso, o termo aquendar é também utilizado como uma ferramenta linguística corpóreo-transgressiva ${ }^{2}$, que permite explorar um lugar de enunciação crítica à normatividade da linguagem de pesquisa em gêneros, corpos, linguagens e suas ressonâncias nos caminhos de investigação (RANNIERY, 2016).

Consideramos de extrema importância a participação de cada uma das entrevistadas durante o projeto que proporcionou $\mathrm{o}$ desenvolvimento desta pesquisa, em especial, a quem o presente texto dedica-se a (d)escrever. As participantes, em suas singularidades, exerceram papéis fundantes para a produção do presente texto, e nosso trabalho não teria sido pensado, sequer escrito, sem a existência destas pessoas, muito menos tido a significação e importância política que tem/teve. Elucubramos aqui algumas memórias numa espécie de timeline que configuram-se de maneira sincrônica em relação ao espaço e tempo da vida destas pessoas. As memórias narradas neste trabalho estabelecem uma relação de evolução de um passado distante até um passado mais recente.

Durante a elaboração do presente texto, buscamos nos alinhar a algumas metodologias que demarcam cientificamente e de forma contributiva a presença de participantes na pesquisa, desvinculando-se de uma perspectiva alteritária, comumente promulgada por diversas áreas do conhecimento científico.

Compartilhamos de métodos que se filiam à desconstrução de uma objetividade científica na prática da etnografia, e no respaldo autoritário que essa posição proporciona ao etnógrafo (WILSSON, 1996, p. 255), tencionando uma futura possibilidade de desconstrução de tal mito, conforme expressa Bonfante (2016, p. 136) "a objetividade pressupõe o objeto como anterior ao discurso que o toca e que lhe atribui seus contornos, ou seja, pressupõe que a linguagem teria a mera função de descrever o mundo social que acaba por construir, estilizar".

As pesquisas científicas desenvolvidas - nos apropriamos de citar aqui principalmente a área das humanidades, dando foco a linguagem analisada nas narrativas - ainda se desenvolvem hegemonicamente visando uma neutralidade dos autores sob o texto, não possibilitando que sejam atribuídas à estas escritas perspectivas e experiências intimas que

${ }^{2}$ Neologismo atribuído pelos autores. 
circundam o autor, sendo assim, produzem e efetivam resultados de maneira limitada.

Em se tratando de excertos coletados e re-entextualizados neste trabalho a partir de entrevistas onde em algumas conversas foram obtidas informações sobre a trajetória de vida e de formação destas pessoas, filiamo-nos a compartilhar e usufruir das teorias metodológicas qualitativas abordadas na entrevista-narrativa (ANDRADE, 2012), por enfatizarmos a importância dessas narrativas em suas diversas formas e contextos, principalmente nos contextos educacionais, como é o caso aqui referido. E também na performance narrativa (BAUMAN, 2004; LANGELLIER, 2001; MOITA LOPES, 2009), considerando o fato de que as narrativas são construídas e performatizadas por seus locutores em quaisquer que sejam os contextos que estejam inseridas, tanto na linguagem, quanto nos signos externos que constroem os usuários destas narrativas.

A performance narrativa [...] se refere a um lugar de embates sobre identidades [...] e não aos atos de um self com uma essência fixa, estável e final que serve de origem [...] De perspectiva da performance e da performatividade, a análise da narrativa não é somente semântica [...] deve ser também pragmática: analisando os embates sobre significados e as condições e consequências de contar uma determinada história de uma determinada forma. A performatividade contextualiza a narrativa nas políticas do discurso, ou seja, redes de relações de poder institucionalizadas. Por exemplo: a medicina, a religião, o direito, a mídia, a família. A narrativa como uma performance situada é particularizada, corporificada e materializada (LANGELLIER, 2001, p.151).

Ao contarmos histórias, (re)escrevemos nossas vivências, narramos nossas memórias, estabelecemos conexões com nossos interlocutores, e construímos nossas identidades, ao mesmo passo que agimos sobre eles em nossas performances que ali estão sendo inscritas. Ao (ins)escrever-se em seus textos ${ }^{3}$, os locutores performatizam sua subjetividade, para que possamos então ter "acesso" e sejamos envolvidos em sua história, para que façamos também parte dela, como seus expectadores. Conforme aponta Moita Lopes (2009, p. 135), "no evento narrativo, os participantes (contadores e ouvintes) estão construindo a vida social de uns aos outros de modos específicos, [...] definidos pelo que os participantes decidem focalizar [na narrativa] [...] e pelo modo como os interlocutores [sic.] se relacionam com eles [e entre si] na performance". 
Nos debruçamos então sobre a construção de performances narrativas identitárias de uma graduanda do curso superior de Letras Vernáculas, na Universidade Federal de Sergipe (campus do interior), que autoidentifica-se e autorreferencia-se como mulher trans ${ }^{*}$, e que precisou desenvolver - durante todo o seu percurso de formação educacional, principalmente ao ingressar no ensino superior na referida universidade - estratégias de negociação e sobrevivência para existir, manter-se e ser respeitada enquanto discente em tais contextos. A estudante demarca-se durante seu processo formativo na universidade como um sujeito, cuja existência e significação corpórea, performativa e identitária, possibilitando a abertura de fragmentos sobre uma ordem hétero hegemônica (MISKOLCI, 2014) instaurada nos contextos educacionais.

Metodologicamente, a pesquisa é influenciada pela abordagem pós-crítica, com a realização de uma entrevista narrativa que ocorreu no mês de dezembro de 2017 e dividiu-se em três momentos específicos: os aspectos da trajetória escolar, as vivências de gênero e sexualidade, e a formação na universidade5. A abordagem narrativa encontrada no presente trabalho desenvolve-se na perspectiva da postulação dos fatos através de memórias, a estudante faz parte do processo de desenvolvimento e configuração do texto. Consideramos nesta escrita, a necessidade de (des)aprender as formas pelas quais fazemos pesquisa, pois investigar pessoas trans* é pesquisar sobre as pessoas trans ${ }^{*}$, com as pessoas trans* e a partir delas (NICOLAZZO, 2017a; 2017b). E isso só é possível com a abordagem narrativa (ANDRADE, 2012), ou seja, uma experiência vivida do cotidiano, sobre o que nos passa, acontece, e nos toca (LAROSSA, 2002).

\footnotetext{
4 As trans-identidades são cada vez mais comumente descritas usando a palavra trans juntamente com um asterisco curinga $(*)$, que é indicativo das muitas identidades possíveis que podem estar associadas à palavra trans (RYAN, 2014; BUTERMAN, 2015).

5 A referida pesquisa foi aprovada pelo Comitê de Ética e Pesquisa da Universidade Federal de Sergipe, sob o parecer de número 1.87392, seguiu a resolução do Conselho Nacional de Saúde de $\mathrm{n}^{0} 466$ de 12 de dezembro de 2012 que versava sobre as diretrizes e normas regulamentadoras de pesquisas envolvendo seres humanos.
} 


\section{O DESABROCHAR DE UMA FLOR: A BELEZA É SUBJETIVA, E CONSTRUÍDA POR INTERMÉDIO DE SUA ESSÊNCIA!}

À Maria ${ }^{6}$ sempre foi negado o direito de existir. De forma que não fosse vista, Maria sempre esteve em ambientes estabelecidos como não sendo seus, assumindo uma posição de outsider, internalizando em sua experiência pessoal a prática de aquendar-se, como sendo sua única possibilidade de existir. Maria sempre acreditou que não fosse como todas as outras garotas, algo de errado acontecia com ela, por que precisava se esconder? As outras garotas do colégio desfilavam e mostravam-se como as mais bonitas, mais charmosas, como se aquele espaço sempre lhes tivesse pertencido, mas com Maria era diferente, ela sempre tivera de assumir a forma e as características de um corpo estranho, do não-padrão, um corpo que foge da norma, não encontrando referente algum com quem pudesse se identificar.

A trajetória de Maria começa no interior do estado de Sergipe, pelas redondezas da cidade de Itabaiana. Moça humilde e de interior, acostumada com os afazeres domésticos e com a vida no campo. Desde cedo, Maria que já era afeita aos traços de Maria, começou a entender ainda em seus primeiros contatos com a educação formal e com o espaço escolar, que sua trajetória em contextos educacionais seria construída de maneira árdua e com alguns estorvos. Tendo em mente tais perspectivas e alguma pouca bagagem de vida, a moça obstinou-se a seguir.

Desde sua infância, Maria narra que sempre sofreu com o estigma de não corresponder às expectativas impostas sobre si, pela heteronorma, sempre fora diferente e carregava consigo as marcas simbólicas e o peso da repressão. É importante destacarmos o contexto onde Maria nasceu e foi criada, e também onde teve acesso aos seus primeiros níveis de escolarização. Maria é advinda da zona rural do estado de Sergipe, um povoado adjacente à cidade de Itabaiana, aproximadamente $50 \mathrm{~km}$ de distância entre a capital do estado.

Numa perspectiva histórico-geográfica e discursiva, temos o Nordeste como uma das regiões onde demasiadamente predominou-se e continua-se perpetuando o mito do "cabra macho sim sinhô", desde a

\footnotetext{
${ }^{6}$ A fim de preservar a identidade de nossa colaboradora na pesquisa, assumimos o papel de rebatizá-la como Maria, construindo junto a força semântica empregada à tal nome, a metáfora de Maria Bonita, esposa de lampião, mulher nordestina, guerreira que fez história em seus feitos e contextos.
} 
construção imagética do sertanejo, do trabalhador rural, e até mesmo da figura ilustre de nossa antítese de herói, o cangaceiro Lampião.

Na região do Nordeste ainda permeia-se por dentre a maioria dos contextos sociais a figura e os discursos do homem valente, trabalhador, macho e viril, que possui força, é destemido, provém proteção e alimento para sua família. Segundo Albuquerque Junior:

A construção da figura do homem nordestino é proveniente dos mitos fundantes da região como o cangaço, os retirantes e o coronelismo, tais discursos tomam ideias regionalistas para estabelecer uma versão molde para a masculinidade do nordestino, baseado de forma essencialista e unitária no sertanejo, elemento este importante na construção discursiva da região Nordeste (ALBUQUERQUE JUNIOR, 2003, p. 162).

A presença de Maria em um ambiente historicamente construído sob a visão de masculinidades predominantes, a força do patriarcado e o machismo enraizado, possibilitou rupturas de gênero de grandes proporções para o determinado contexto.

Nem sempre Maria foi Maria, porém sempre quisera ser. Nasceu, foi batizada e cresceu sob normas que se destoavam de sua existência: Maria sempre foi tida como Lampião! Mas no decorrer de sua vida, entre o viver e experimentar-se enquanto sujeito - além das diversas vezes em que teve seu reflexo refletido no espelho e não deu-se por satisfeita começou a identificar-se de fato como Maria. Oh, Maria! Figura formosa, sensível, de bom agrado, uma flor de sertão. A figura de Lampião que fora estabelecida e controlada socialmente no corpo de Maria foi aos poucos deixando de existir, e aos poucos também foi se abrindo espaço para que naquele corpo fosse inscrita a verdadeira figura de Maria, e desaquendouse. Numa concepção Focaultiana, é possível pensar "o corpo como uma jaula desagradável, na qual terei que me mostrar e passear. É através de suas grades que vou falar, olhar, ser visto. Meu corpo é o lugar irremediável a qual estou condenado" (FOUCAULT, 2014, p. 01).

Segundo a proposição apresentada pelo autor, é possível conceber o corpo como uma figura paradoxal, cercada de significados (préconstruídos e postos em questão) e oportunidades de experimentações. Ao mesmo passo que "me observo"7 materializado corpóreamente, me desencontro; estou preso em minha própria materialidade, mas me comunico através de minhas grades, de meus dispositivos de

7 A utilização da primeira pessoa no singular funciona aqui como uma "mostra explicativa" para que todes leitores possam se colocar no local da experimentação de sujeito a quem se refere. 
comunicação. Sou visto, e me reconstruo diante do outro, estou salvo, mas ao mesmo tempo condenado a mim mesmo. O corpo e o devir sujeito são construídos discursivamente e semioticamente ${ }^{8}$ através dos diversos símbolos e discursos inscritos sobre si, que os circundam, numa espécie de "ponto de partida e espaço de fuga" para auto referenciar-se no processo de construção. Consoante Borba (2016, p. 78):

Tornar-se um tipo reconhecível de sujeito, para usar a retórica foucaultiana, não acontece em um momento específico e bem demarcado da história social de um indivíduo; os efeitos materiais dos dispositivos, as técnicas de si, não aparecem repentina e abruptamente. Pelo contrário, atuam paulatinamente sobre os corpos e as subjetividades daqueles/as que capturam em suas engrenagens de saber/poder. O sujeito seria, assim, o resultado cumulativo de uma sucessão de encontros discursivos intertextualmente ligados entre si. Aquilo que chamamos de identidade, a partir dessa abordagem, passa a ser entendido como uma projeção semiótica dialógica e situada, orientada pela história de interações passadas e futuras com outros/as, tendo seus efeitos pragmáticos locais moldados por essa história translocal.

Durante sua experiência de subjetivação, Maria experimentou diversas formas de si mesma, performatizando gêneros, linguagens, discursos, e atribuindo a si mesma signos lidos socialmente como femininos, reiterando-se continuamente em todo esse processo.

Durante a conversa que tivemos com Maria, nos foi informado sobre sua identificação de gênero, o feminino, e que atualmente não existe nenhum tipo de restrição para referir-se a ela utilizando o sufixo trans*, mas nem sempre foi assim. Maria conta que nem mesmo tinha passado ainda por sua completa "desaquendação de gênero", ou seja, ainda não tinha estabelecido consigo mesma a ideia de uma transição e já sofria no ambiente escolar as consequências por não atender às heteronormatividades impostas por aquele espaço.

Nossa, foi o pior período da minha vida, pior período desde o ensino fundamental! Porque eu sempre sofri muito bullying, né? que hoje eles chamam de bullying...

Eu era tratado como viado a vida toda, por todo mundo, viadinho ... e não sei o que ... e foi no ensino fundamental, tenho a certeza que foi o pior período da minha vida, porque pra sair da escola, pra você ter uma

${ }^{8}$ Sendo a semiótica uma ciência dos signos, "é possível dizer que tudo pode ser signo, pois, uma vez que somos seres socializados, aprendemos a interpretar o mundo que nos cerca" (MARTINE, 1996, p. 29) 
ideia, pra eu sair da escola eu tinha que esperar, eu estudava à tarde, eu tinha que esperar todo mundo sair da escola, liberar a escola, todo mundo: professor, aluno, funcionário, só ficava o vigilante ... ficava um monte de moleque lá no muro e pra eu sair de lá eu tinha que sair quando as pessoas já estavam indo embora, e aí ficavam na frente do colégio e me acompanhavam até dentro de casa, com aquela chacota, com aquela "chamação" de gay, de viadinho e não sei o que, até esse bocado eu já vi, até pedra jogavam em mim, né? e aí isso cria um trauma psicológico muito grande em minha vida. Eu não conseguia olhar pra mim, eu não conseguia nem me olhar no espelho, quando chegava em casa eu só fazia me trancar no quarto e ficava, não comia, não saía, não saía pra lugar nenhum [...] (MARIA, 2017).

O ambiente escolar/contexto educacional adquiriu uma significação traumática na experiência de vida de Maria, que sempre se sentiu ameaçada psicologicamente, verbalmente e fisicamente em decorrência de suas experiências nos primeiros anos ao frequentar um espaço de formação intelectual. Ao narrar que todos os dias, ao sair da escola, esperava o espaço esvaziar para que então pudesse seguir para casa, Maria nos explicita uma de suas estratégias de não ser percebida dentro da escola. Ou seja, o silenciamento de seu corpo era uma forma de não ser vista, pelo receio de sofrer alguma situação de assédio ou violência de gênero. As experiências relatadas por Maria se configuram como parte de um heteroterrorismo (BENTO, 2011), ao qual foi submetida durante seus anos de educação formal. Em outro excerto Maria diz:

Eu não conseguia me olhar no espelho de forma nenhuma, eu tinha vergonha, e quando eu sentava na cadeira da sala, eu ficava só de cabeça baixa, não olhava para o lado, não olhava para o professor, não respondia chamada, não saia para o intervalo, chegava, entrava e na saída ia embora, só e pronto. Principalmente quando a gente pega transporte público né, e aí também no ônibus aquela mesma coisa, se eu passasse em algum lugar, por mais que eu tentasse ser despercebida, mas todo mundo percebia e todo mundo começava, com toda essa mangação e xingamento de novo (MARIA, 2017).

Não se perceber no espelho, enseja à Maria uma internalização da promulgada "estranheza" que tanto era apontada em seu corpo. Sua inconformidade corpórea escapava às normas de gênero. Desde sua infância, Maria nunca possuiu a masculinidade exigida para o corpo de um menino dentro da escola.

De diferentes modos, os sujeitos que se configuram corpóreamente ou performaticamente (BUTLER, 2003; BENTO, 2017) 
escapando às normas estéticas e comportamentais estabelecidas pela sociedade, estão propensos a sofrer violências de gênero das mais variadas maneiras. De acordo com Bento (2011, p. 551):

As experiências de trânsito entre gênero demonstram que não somos predestinados a cumprir os desejos de nossas estruturas corpóreas. O sistema não consegue a unidade desejada. Há corpos que escapam ao processo de produção dos gêneros inteligíveis e, ao fazê-lo, se põe em risco porque desobedeceram às normas de gênero, ao mesmo tempo revelaram as possibilidades de transformação dessas mesmas normas. Esse processo de fuga do cárcere dos corpos-sexuados é marcado por dores, conflitos e medos.

Ao darmos enfoque e analisarmos as situações narradas, é perceptível como até então a estranheza do corpo de Maria, não modelado ou que não possuía nenhuma aderência a uma determinada performance binária de gênero, colocava em risco todo um contexto social e um grupo específico. Assim concebemos a heteronormatividade como "[...] um conjunto de prescrições que fundamenta processos sociais de regulação e controle" (MISKOLCI, 2009, p. 156), em que predominam discursos nos quais a reprodução e a heterossexualidade se associam à ideia de família, que reiteram-se como um padrão a não se escapar, e isso é feito constantemente através de práticas e discursos, como por exemplo em alguns dos excertos analisados na presente narrativa: "Me acompanhavam até dentro de casa, com aquela chacota, com aquela "chamação" de gay, de "viadinho" e não sei o que ... até pedra jogavam em mim né, e aí isso cria um trauma psicológico muito grande em minha vida" (MARIA, 2017).

Analisando os excertos das falas de Maria, temos a oportunidade de perceber o discurso como um dos fatores primordiais, onde circundam suas performances narrativas. Também podemos observar nas entrelinhas dessas manifestações discursivas os efeitos pragmáticos que são gerados sobre os sujeitos participantes nestes processos de interação. Ao concordarmos com Bauman e Briggs (1990) sobre o fato de que em nossas performances narrativas construímos a nós mesmos e atingimos aos outros, podemos entender melhor como se configura o efeito pragmático dessa narrativa, e como essas ações linguísticas possuem um "resultado" nos locutores e interlocutores.

Maria utiliza-se de alguns termos para se autorreferenciar e demonstrar a nós, interlocutores, como era tratada nas situações de violência que viveu. Ao nos atermos à estas situações de violência verbal 
descritas por Maria, é clara a denominação que ela dá e como ela descreve tais acontecimentos, como uma espécie de "chamação", nos momentos em que os "moleques" que estavam na região da escola ou no caminho para sua casa buscavam lhe ofender, se fazendo valer de termos com uma carga semântica pejorativa, como "gay" ou "viadinho", "recortando as expressões de um contexto social específico e as aplicando a um novo contexto" (BENTO, 2017, p.87). Segundo a autora:

Quando alguém diz "veado" ou "sapatão", não está emitindo uma opinião pessoal; está efetivando uma operação de recorte e colagem. Ao retirar a expressão do contexto social mais amplo em que ela foi tantas vezes enunciada, realiza-se a primeira operação: o recorte. Depois, ocorre o encaixe em um novo contexto, no qual ela reaparece escamoteada como uma opinião pessoal, mas de fato, que é uma citação ressignificada a novos contextos.

Ao praticarem estes xingamentos contra Maria, tais "emissores" não estavam apenas realizando um recorte de expressões para um novo contexto, mas estavam também utilizando-se de tais elementos linguísticos e prosódicos para se referir a um outro sujeito com uma força pejorativa. A execução de um discurso de ódio (hate speech) por parte de tais locutores tinha a intenção de provocar efeitos em quem essas palavras e ofensas foram direcionadas.

Refletimos então acerca das performances discursivas-narrativas produzidas na/e através da linguagem, entendendo os efeitos físicos e psicológicos produzidos sobre um sujeito pelo ato de narrar/falar. Neste sentido, é possível dizer ainda que ao produzirem tais ações através da linguagem, ou produzirem atos perlocucionários ${ }^{9}$ através destas performances, os locutores provocam efeitos e materializam ações.

A incapacidade de um não reconhecimento ou de identificação de si própria no reflexo do espelho nos aponta pistas das marcas da violência de gênero que foram empreendidas contra Maria, lhe impedindo de desenvolver-se de forma livre e de construir sua subjetividade como qualquer outra pessoa, sem experiências traumáticas.

As injúrias e violências de gênero que Maria enfrentou durante sua desaquendação nos anos iniciais do colégio não foram suficientes para lhe impedir de continuar em seu processo - tácito - de resistência. De acordo com Maria (2017):

\footnotetext{
9 O ato perlocucionário - é um ato realizado "por dizer algo", consiste nos efeitos alcançados pelos atos de fala, como: convencer, comover, alarmar, obrigar, etc. (AUSTIN, 1990).
} 
Minha vida só começou realmente depois que eu iniciei o tratamento psicológico ... e aí eu também comecei a fazer ensino médio, e no colégio era maior, com pessoas mais ou menos como eu, daí eu fui ver que não era essa aberração que eu imaginava que eu era... na verdade, de tanto ser imposto isso pelas pessoas, eu me imaginava dessa forma.

No decorrer de nossa conversa com Maria, fomos entendendo sobre o caminho que teve de ser percorrido até seu ingresso no ensino superior. Maria conta que o que mais temia ao ingressar na universidade era que seus antigos pesadelos e traumas pudessem se repetir, lembrando vividamente todas as situações que já havia enfrentado:

Já passei do ensino médio e tudo, fui para minha vida atual, mas quando eu entrei na universidade eu já sabia o que eu era, eu tinha consciência de tudo que eu era, eu só tinha medo do que eu ia enfrentar por ter enfrentado tanta coisa no ensino fundamental e no ensino médio, eu tinha medo do mundo que eu ia encontrar aqui dentro, entendeu? (MARIA, 2017).

Ao ingressar no ensino superior, Maria teve a oportunidade de conhecer uma realidade um tanto quanto diferente da que já conhecia na educação básica. Os contextos educacionais estabelecidos aqui nesta discussão, tanto a instituição de educação básica (ensino fundamental e médio), quanto na instituição de ensino superior, sempre funcionaram como espaços reguladores de poder e de sujeitos; todos os discursos produzidos e transmitidos dentro desses microcosmos produziram efeitos nos sujeitos que os constituíram. Consoante com Franco e Ciciclini (2015, p.328, grifos nossos):

Ao contextualizarmos as posições de sujeito ocupadas por pessoas trans na escola, constatamos que são posições constituídas pelo resultado de processos constantes de resistências e enfrentamentos advindos da educação básica e também da educação superior. Essas pessoas representam uma pequena parcela de pessoas trans que conseguiram suportar as imposições heteronormativas em razão da vulnerabilidade social à qual foram expostas desde as fases iniciais da Educação Básica, associadas a processos de exclusão anteriores.

O objetivo de Maria ao adentrar o espaço universitário a priori não era de subverter ou transgredir nenhum tipo de norma estabelecida neste espaço, mas apenas inserir-se e ter acesso a uma formação de nível superior, para que assim, pudesse ser reconhecida enquanto sujeito social 
ativo, escapando à ideia pré-estabelecida e promulgada socialmente, de que as mulheres transexuais estão relegadas aos submundos, cargos em empregos que não possuem prestígio ou à prostituição. Em sua narrativa, Maria conta que entrar na universidade seria um dos passos mais grandiosos que estaria dando, sendo a primeira de sua família a ingressar no ensino superior.

Aqui dentro eu sabia o que eu queria, sabia onde eu ia chegar e tinha um pensamento de que um dia voltaria por cima, sabe? sem ninguém me tratar como já me trataram, sempre tive essa meta na minha vida, não ser uma trans que fica parada na esquina fazendo programa, não ser uma trans que vira cabeleireira, não ser somente uma trans. Eu sou uma trans, e eu sou universitária (MARIA, 2017).

Questionamos então as "bordas sociais" e os espaços que são relegados aos sujeitos que fogem da cisnomatividade. Quais são os espaços que lhes cabem? Qual é a relevância atribuída para um corpo que destoa da cisnorma ao adentrar tal contexto? Compreendemos a universidade onde Maria está matriculada, como um campo de forças e embates entre às cisnormas perpetuadas por tal contexto e os sujeitos sociais que lhe configuram. As possíveis relações que ali se estabelecem sempre irão estar pautadas em uma busca hierárquica de poder, seja pelos bens culturais que esse campo produz, ou seja, pelos sujeitos que ali se constituem.

A instituição enquanto espaço detentor de poder e discursos hegemônicos continua perpetuando rejeitabilidades para todo e qualquer sujeito que fuja aos padrões que foram construídos, reiterados e conduzidos desde sua criação, através de seus agentes, discursos e performances pautadas na cisnormatividade. A cisnormatividade ou heteronormatividade é o padrão dominante que perpetua-se nestes espaços formativos. Segundo Pocahy (2016, p. 13):

A cisnorma consiste na manutenção de privilégios dirigidos à pessoas supostamente consideradas coerentes ao sistema corpo-gênero (anátomo-gendradas). Essa posição privilegiada teria como efeito regulatório e hierarquizador a interpelação abjeta e patologização da transexualidade - e mais amplamente da transgeneridade [...]. De outra parte, e em consonância às proposições supracitadas, recorro à ideia de hetero/homocisnormatividade como forma de evidenciar os efeitos desses ideais regulatórios de gênero, que estariam associados à suposta naturalidade do corpo (através da linha de inteligibilidade corpo>gênero->sexualidade - uma matriz fundacional) e sua articulação 
com os privilégios daí decorrentes. Note-se com isso que a cisnormatividade também marcaria posições privilegiadas para aquelas pessoas que de alguma forma também poderiam ser consideradas desviantes (agora apenas do ponto de vista da sexualidade - ou “orientação sexual”). Isto é, a cisnormatividade compreende as posições gay e lésbica, igualmente. E no caso de uma performance normativa, seu correspondente seria a homocisnormatividade.

Maria adentrou o campus da universidade provocando rupturas nas heteronormas que circundam o espaço educacional formal. Simbolicamente, Maria possui uma presença e um corpo-político, que diverge dos inúmeros pressupostos sociais. Os signos adotados para a construção de uma figura feminina, seu modo de falar, seu modo de portar-se produz e reproduz perfomatividades (BUTLER, 2003; MOITA LOPES, 2009; LANGELLIER, 2001) em conformidade ao gênero que ela se identifica.

Durante as aulas na graduação, Maria sempre se apresentou com identificação feminina, pedindo aos docentes e colegas que fosse tratada em concordância com seu gênero, principalmente no tocante a utilização de seu nome social. Apesar de toda cautela adotada por Maria para que tivesse seus direitos e sua identidade respeitada, ela não os teve, e mais uma vez foi vítima de uma violência de gênero institucionalizada/transfobia ${ }^{10}$. Maria nos conta sobre os primeiros episódios ao adentrar a universidade: "Todo mundo me tratando como um homem, mesmo que eu fosse mulher, mas todo mundo me tratava como um homem, principalmente os professores (MARIA, 2017)"11. O excerto da narrativa nos mostra de forma evidente que as posições hierárquicas dos docentes da instituição lhes asseguram esse tipo de tratamento para com uma estudante transexual, tendo em vista que até o momento nem na própria instituição, quanto nos regimentos nacionais existia nenhuma lei, regimento ou portaria que protegesse sua identidade de gênero.

Nossa, eu só faltava cavar um buraco no chão e me enterrar, né? Eu até tinha colegas que diziam: não professor, ele é ela! e eu ficava meio sem graça né, mas isso é.... assim, os meus colegas falavam isso na frente da

\footnotetext{
${ }^{10}$ Segundo Torres e Prado (2014), a transfobia e seus correlatos funcionam como dispositivos dinâmicos da heteronormatividade, provocando prejuízos a toda educação (RAMIRES, 2011; PRADO; JUNQUEIRA, 2011), pois esses dispositivos, ao produzirem as relações sociais, o fazem estabelecendo hierarquias em que LGBT, entre outros, são definidos em processos de subalternização, tendo menos acesso e reconhecimento.

${ }^{11}$ [Referência Suprimida] também evidenciaram outra experiência de transfodia institucional vivido por uma outra estudante trans* no ensino superior.
} 
turma inteira, mas isso continuava, o mesmo professor .... Aí os meninos falavam assim: não professor quem é ele, quem é ele? Você está vendo algum homem aqui? É uma mulher, não é homem, daí eles ficavam meio sem graça ... mas assim, para eles tanto faziam (MARIA, 2017).

A (re)produção de uma heteronormatividade compulsória em nossa sociedade e nos contextos sociais também são frutos de padrões cisnormativos hegemônicos que demarcam os corpos a partir de sua materialidade sexual biológica.

Podemos perceber que não há espaço para expressões que não coadunem com a matriz cultural heteronormativa e binária na universidade, pois, neste espaço, as posições masculinas e femininas são instituídas a partir de normas que regulam e determinam a impossibilidade de existência fora de seus moldes. (DIAS; ZOBOLI; SANTOS, 2018, p. 174).

Fazer parte do espaço acadêmico-universitário sempre foi um dos principais objetivos de Maria, mas como manter-se em uma ambiente que lhe oculta e lhe nega sua própria existência? Existe a possibilidade de manter-se ou efetivar-se em um contexto que aquende seus discursos e narrativas, e lhe negue sua condição de sujeito?

Frente à necessidade da reconfiguração de uma falida heteronormatividade compulsória em relação as pessoas desviantes de gênero, surge a necessidade de criação de micropolíticas de subjetivação e (re)existência. O processo de desanquendação de Maria se fez necessário, não somente enquanto sujeito que busca ser reconhecido em suas próprias vivências e performances de gênero, mas também como sujeito ativo, como estudante, como percursora de micro-estratégias políticas de efetivação. Maria compartilha conosco a ideia de negociação, era necessário negociar sua existência, um embate agressivo não teria eficácia alguma, tendo em vista que no sistema heteronormativo onde ela se encontrava, ela era considerada uma outsider. Era preciso infiltrar-se nas normas, aderindo-se a elas, e ao mesmo passo, tentar fazer com que essas normas fossem desconstruídas e desestruturadas, através de discursos, posicionamentos, e até mesmo de sua presença.

As performances narrativas de Maria, contribuem para demarcar sua existência enquanto pessoa trans* na universidade, sua posição enquanto locutora afetava os outros interlocutores (professores, colegas, funcionários) da universidade. Narrar-se e discursivisar-se verbalmente e semioticamente através de todos os signos que foram/são empregados em 
sua corporeidade faz parte de seu processo de desaquendação. Segundo Borba (2016, p. 105):

Nas trajetórias de socialização durante as quais performances narrativas são forjadas e determinados tipos de sujeitos emergem localmente, os processos de entextualização, descontextualização e recontextualização podem ser operacionalizados por meio de detalhes narrativos, discurso reportado, paralelismos, apelos à audiência, itens paralinguísticos, gestos [...]

Maria não foi a única estudante trans* que teve seus direitos sociais negados durante seu percurso na referida Universidade. Em um outro campus, uma graduanda - também de letras-, mulher trans*, militante dos direitos LGBTQI+ sofreu transfobia por parte de um docente da mesma instituição, porém, essa outra estudante precisou acionar um processo administrativo contra este docente, devido ao não uso de seu nome durante às aulas na graduação e as frequentes humilhações que lhe vinham sendo conferidas. Devido à repercussão do processo administrativo e com o apoio de algumas outras estudantes e militantes das causas LGBTQI+ para que a universidade se posicionasse em relação ao tratamento e uso de nome social em todas as esferas e instâncias de maneira institucionalizada, foi declarado e assegurado em uma resolução ${ }^{12}$, o uso do nome social na universidade.

As conquistas histórico-transgressivas que partem das atitudes e do posicionamento das estudantes transexuais que compõem o corpo discente da Universidade muito significam, essas mudanças institucionais funcionam como verdadeiras rupturas sistêmicas, uma desaquendação política de suas existências enquanto sujeitos, é uma busca por reconhecimento no mundo, em espaços e contextos que nós, seres sociais precisamos estar. Mesmo sabendo que não existe uma totalidade quanto a estas questões, e que não há um reconhecimento perfeito, não significa que precisamos parar de nos desaquendarmos diante disso, e que mesmo assim nos posicionemos nessa constante. Assumir uma posição de coletividade é traduzir essa coletividade em força política e notabilidade enquanto corpos e sujeitos. Segundo Butler (2016, p. 28):

Eles fazem isso em solidariedade uns com os outros, não enquanto indivíduos heroicos. Mas, ainda assim, se nós vivemos em um mundo

12 Portaria No 2209 de 18 de Junho de 2013, que regulamenta o uso do nome social de travestis e transexuais nos registros acadêmicos da Universidade Federal de Sergipe. 
onde os corpos somente são compreendidos dentro das normas convencionais de gênero, ou quando aquelas pessoas que são excluídas da sociedade são tidas como as não civilizadas, então como essas vidas se tornam visíveis e audíveis em tais condições? Como podem os corpos serem reconhecidos quando eles não se encaixam na norma social do que os corpos deveriam ser? Que atos de agência são necessários para enfrentas as forças de exclusão e desrealização e também de violência como os corpos se reúnem para significar sua existência, sua inteligibilidade e sua persistência? Algumas vezes é o próprio ato de se levantar, de caminhar juntas e de se reunir que afirma uma existência social, traz significado a uma demanda política e promete um futuro político diferente (BUTLER, 2016, p.28).

Os atos de Maria, dentro do contexto em que se encontrava, funcionaram como micropolíticas de sobrevivência e existência, estratégias de negociação para que ela pudesse manter-se estudando e não desistisse da graduação. Conforme percebemos em sua narrativa, ela sempre teve ciência de quanto as coisas iriam evoluir e de que forma ela conseguiria subverter as situações de violência e preconceito que constantemente era submetida.

Através de tais performances narrativas, conseguimos identificar resistências e ações-políticas praticadas e reproduzidas por essas estudantes contra os discursos cis/heteronormativos incorporados e reiterados por estes espaços e instituições educacionais. Através de fragmentos gerados por micropolíticas e desaquendações que foram e vem sendo instauradas, é possível identificar o quão significativas são estas ações contra esse silenciamento/aquendamento institucional. Aquendamos aquilo que não pode, não deve e não se quer ver, aquilo que de certa forma causa estranhamento e incomodo no(s) outro(s). Foi preciso recategorizar sua existência, assumir um lugar de fala, ser notada e ser ouvida, assumindo também o espaço de sujeito a quem se vale a vida.

\section{Considerações Finais}

Cactus, palavra derivada do grego Kaktos, empregada antigamente para designar uma espécie de cardo espinhoso, no nordeste, principalmente no sertão conhecemos o cacto como uma flor. Flor do sertão, bruta e espinhosa, que consegue sobreviver as intempéries do tempo mas que nunca, ou por quase motivo algum perde a sua beleza e sua força de existir. Além da beleza estética, o cacto, ou a flor do sertão, como assim preferirmos chamar, possui diversas características físicas e 
de adaptação. Ele pode ser encontrado facilmente em ecossistemas como os desertos, semiáridos, catingas e cerrados, possui uma incrível habilidade de acumular a pouca água que recebe, e assim consegue sobreviver, mesmo a todos os fenômenos aos quais é exposto na natureza. Até mesmo a flor do sertão precisa de estratégias de sobrevivência, de negociar-se em seu habitat para que consiga sobreviver e florescer. Maria, em seu contexto não-pertencente, metaforseou-se e desaquendou-se enquanto flor, e reinventou sua existência. Através desses não lugares e posições outras de não-sujeito, em contextos que sempre lhe contestaram a existência, lhe regularam e lhe dominaram apoiando-se em suas diferenças, Maria aprendeu a tecer rasuras estratégicas que mais funcionaram como escudos de sobrevivência dentro da universidade. Tal flor demonstrou força e resiliência para lidar com as intempéries estabelecidas em seu habitat, (re)construindo sua história e subvertendo as histórias que foram pré-estabelecidas para sua existência.

A existência de Marias dentro dos espaços formais de ensino, em específico à referida instituição onde se desenvolve esta narrativa, exerce uma constante micropolítica de (re)negociação e de (re)existência (DIAS, 2018; Dias, 2020). As dissidências ali presentes, se (des)arrumam para dar espaço à novas formas de subjetivação. As perturbações de gênero permitem a construção de narrativas outras, de um espaço e de uma pesquisa onde Maria habita-resiste (POCAHY, 2016; DIAS, 2018; DIAS, 2020). O que esteve em jogo durante toda a vivência acadêmica para Maria foi existir, ser notada e ser reconhecida por sua existência, para isso, foi preciso desconfigurar-se e reconfigurar-se, aquendar-se $\mathrm{e}$ desanquendar-se, foi preciso o tempo todo se (re)negociar enquanto pessoa (JAEKEL; NICOLAZZO, 2017).

Essas micropolíticas de existência, também podem ser lidar como lutas que foram empreendidas em movimento da liberdade e do reconhecimento dos sujeitos envolvidos. Tais ações vêm produzindo efeitos importantes, como também rupturas nas cisnormatividades reiteradas por diversos contextos e espaços sociais. São narrativas como essas, de pessoas tidas como insurgentes que proporcionam tais mudanças relacionadas aos processos de subjetivação. Consoante a Pochay (2016, p.16), é preciso entender que “... as micropolíticas ensejam operar em reafirmação de que olhar-sentir-fazer-existir, é desde sempre tecido em redes de saber-poder. Maria desaquenda-se de forma entendível para sua existência, "desterritorializando-se de uma heteronormatividade" compulsória e binária que sempre lhe foi lhe colocada/imposta como norma. Da mesma maneira que o cacto se utiliza 
de sua biologia e de tudo que foi dado pela natureza para poder se constituir, reinventar e resistir, Maria utiliza-se de suas diversas ferramentas de gênero, discurso e existência política para se constituir e existir.

\section{Referências}

ALBUQUERQUE JUNIOR, Durval Muniz. Nos destinos de fronteira: história, espaços e identidade regional. Recife: Bagaço, 2008.

ANDRADE, S. A entrevista narrativa ressignificada nas pesquisas educacionais pós-estruturalistas. In: MEYER, Dagmar Estermann; PARAÍSO, Marlucy Alves (Org.). Metodologias de pesquisas pós-críticas em educação. Belo Horizonte: Mazza, 2012. p. 173-194.

AUSTIN, J. L. Quando dizer é fazer. Porto Alegre: Artes Médicas, 1990.

BAUMAN, R.; BRIGGS, C. Voices of Modernity: Language Ideologies and the Politics of Inequality. Cambridge: Cambridge University Press, 2003.

BUTERMAN, Jan. Meantime: a brief personal narrative of a trans* teacher. Canadian Journal of Educational Administration and Policy, Issue 173, November 9, 2015.

BENTO, B. A Reinvenção do Corpo - Sexualidade e gênero na experiência Transexual. $1^{\mathrm{a}}$ ed. Salvador, BA: Editora Devires, 2017.

BENTO, B. Na escola se aprende que a diferença faz a diferença. Estudos Feministas, vol. 19, n. 2, maio-agosto, 2011, pp. 549-559.

BORBA, R. (Des)aprendendo a "ser": trajetórias de socialização e performances narrativas no processo transexualizador. Rio de Janeiro, 2014, 206 p. Tese de Doutorado apresentado ao Programa Interdisciplinar de Pós-Graduação em Linguística Aplicada, Universidade Federal do Rio de Janeiro.

BONFANTE, G. M. Erótica dos signos em aplicativos de pegação: processos multissemióticos em performances intímo-espetaculares de si. Rio de Janeiro, 2016. 
BUTLER, J. Corpos que ainda importam. In: COLLING, L. (Org.). Dissidências Sexuais e de Gênero, Salvador, EDUFBA, 2016. p.20-42.

BUTLER, J. Problemas de gênero: feminismo e subversão da identidade. Rio de Janeiro: Civilização Brasileira, 2003.

Dias, A. F. Trans* escrevivências as a pedagogical power. Journal of Research and Knowlege Spreading, v. 1, n. 1, pp. 1-17, 2020. https://doi.org/10.20952/jrks1111494

DIAS, A. F. Formative and professional narratives of a transsexual teacher. Educ. rev., Curitiba, v. 34, n. 70, p. 255-271, 2018.

https://doi.org/10.1590/0104-4060.57415.

FOUCAULT, M. O corpo utópico. 2014. Texto disponível em: $<\mathrm{http}$ ://www. ihu. unisinos. br/noticias/38572-o-corpo-utopicotextoinedito-de-michel-foucault $>$.

FOUCAULT, M. A Ética do Cuidado de si como Prática da Liberdade. In: Ditos e Escritos. Rio de Janeiro: Forense Universitária, 2010.

FOUCAULT, M. História da Sexualidade I: a vontade de saber. 19. ed. Rio de Janeiro: Edições Graal, 1988a.

FRANCO, N. CICILLINI, G. Professoras trans brasileiras em seu processo de escolarização. Estudos Feministas, Florianópolis, 23(2): 352, maioagosto/2015,

JAEKEL, K. S.; NICOLAZZO, Z. Teaching trans*: Strategies and tensions of teaching gender in student affairs preparation programs. Journal for the Study of Postsecondary and Tertiary Education, 2, 165-179, 2017. https://doi.org/10.28945/3859

LAROSSA, Jorge. Notas sobre a experiência e o saber da experiência. Revista Brasileira de Educação, n. 19, p. 20-30, 2002.

LANGELLIER, K. 'You're Marked': Breast Cancer, Tattoo, and the Narrative Performance of Identity. In.: BROCKMEIER, J.; CARBAUGH, D. (eds.), Narrative and Identity: Studies in Autobiography, Self, and Culture. Amsterdam: John Benjamins, 2001, p. 145-184. 
LISPECTOR, C. A hora da Estrela. Rio de Janeiro: Rocco, 1988.

MARTINE, Joly. Introdução à análise da imagem. Campinas: Papirus, 1996.

MISKOLCI, R. 2009. A Teoria Queer e a Sociologia: o desafio de uma analítica da normalização. Sociologias. Porto Alegre, ano 11, $\mathrm{n}^{0}$ 21, jan./jun. 2009, p. 150-182.

MISKOLCI, R. 2014. Negociando visibilidades: segredo e desejo em relações homoeróticas masculinas criadas por mídias digitais. BAGOAS, Rio Grande do Norte, n. 11, p. 51-78

MOITA LOPES, L. P. A performance narrativa do jogador Ronaldo como um fenômeno sexual em um jornal carioca: multimodalidade, posicionamento e iconicidade. Revista da ANPOLL, v. 27, p. 129-160, 2009.

NICOLAZZO, Z. Imagining a Trans* Epistemology: What Liberation Thinks Like in Postsecondary Education. Urban Education, 1-26, 2017a. DOI: 10.1177/0042085917697203.

NICOLAZZO, Z. Trans* in college: Transgender students' strategies for navigating campus life and the institutional politics of inclusion. Sterling, VA: Stylus, 2017b.

PRADO, Marco Aurélio Máximo; JUNQUEIRA, Rogério Diniz. Homofobia, Hierarquização e Humilhação Social. In: VENTURI, Gustavo; BOKANY, Vilma (Org.). Diversidade Sexual e Homofobia no Brasil. São Paulo: Editora Fundação Perseu Abramo, 2011. P. 51-72.

POCAHY, F. (Micro)políticas queer: dissidências em pesquisa. Textura, v. 18 n.38, set./dez.2016

PRECIADO, B. Multidões queer: notas para uma política dos "anormais". Estudos Feministas, Florianópolis, 19(1): 11-20, janeiro-abril/2011.

RANNIERY, T., No meio do mundo, aquendar a metodologia: notas para queerizar a pesquisa em currículo, Práxis Educativa, Ponta Grossa, v. 11, 
n. 2, p. 332-356, maio/ago. 2016. ISSN 1809-4309 (Versão online). DOI: 10.5212/PraxEduc.v.11i2.0002

RAMIRES, Luiz. Homofobia na Escola: o olhar de um educador social do movimento LGBT. In: VENTURI, Gustavo; BOKANY, Vilma (Org.). Diversidade Sexual e Homofobia no Brasil. São Paulo: Editora Fundação Perseu Abramo, 2011. P. 131- 140.

RYAN, H. What does trans* mean, and where did it come from? [Web log post]. Slate. 2014. Retrieved in January 10, from Disponível em: <http://www.slate.com/blogs/outward/2014/o1/10/trans_what _does_it_mean_and_where_did_it_come_from.html $>$. Acesso em: 04 out. 2018.

TORRES, M. PRADO, M. Professoras Transexuais e Travestis no Contexto Escolar: entre estabelecidos e outsiders. Educação \& Realidade, Porto Alegre, v. 39, n. 1, p. 201-220, jan./mar. 2014.

WILLSON, M. Perspective and difference: sexualization, the field, and the ethnographer. In: KULLICK, D.; WILSON, M. (Eds.). Taboo: sex, identity and erotic subjectivity in anthropological fieldwork. New York: Routledge, 1996. 


\section{Hidden narratives: (micro)politics of negotiation established by a trans* student in the high education}

RESUMEN/ABSTRACT: The purpose of this text is to reflect on the formative process of a trans student, from the micro-politics of resistances and the negotiations of sexuality and gender developed in higher education. In this text was used a post-critical qualitative method, trough the execution of a narrative interview, where this student tells the violences cases that happened to her and also the daily struggles in. The narratives confirm the transphobic experiences lived by the student during her schooling process, mainly during ar the university, as well as it shows possibilities of existence and negotiation about gender learning in the university, in a process of aquendar-se and desanquendar-se (hide and unhide), being necessary to re-negotiate herself as a trans person.

Palabras Clave/Keywords: Negotiation of Gender. Trans* Student. High Education.

\section{Madson de Santana Santos}

Graduado em Letras Português/Inglês pela Universidade Federal De Sergipe. Ex-Bolsista de Iniciação Científica do CNPq. Integrante do Grupo de Pesquisa: Educação, Formação, Processo de Trabalho e Relações de Gênero - CNPq . Atualmente desenvolve pesquisas nas seguintes áreas: Gênero e Sexualidade, Educação e Linguística.

E-mail: madson341@gmail.com

\section{Alfrancio Ferreira Dias}

Doutor em Sociologia (UFS). Professor do Programa de Pósgraduação em educação da Universidade Federal de Sergipe. Bolsista de Produtividade em Pesquisa 2 (CNPq). E-mail: diasalfrancio@gmail.com.

Recebido em: 20/08/202O

Aprovado em: 27/01/2021 